\title{
De la sodomía a la superstición: el pasivo activo y transgresiones corporales en la Nueva España*
}

From Sodomy to Superstition: The Active Pathic and Bodily Transgressions in New Spain

Laura A. Lewis ${ }^{\text {a }}$

DOI: https://doi.org/10.11144/Javeriana.cl25.sspa

University of Southampton, Reino Unido

1.lewis@soton.ac.uk

ORCID: https://orcid.org/0000-0003-2782-7254

Recibido: 11 Julio 2019

Aceptado: 11 Octubre 2019

Publicado: 20 Agosto 2021

\section{Resumen:}

Por medio de documentos primarios y debates académicos, este artículo examina una serie de prácticas en el México colonial que revelan cómo las ideologías de género informaban las políticas de disciplinamiento, así como una serie de comportamientos que iban desde la sexualidad atípica hasta el travestismo y la brujería. De este modo, nos habla de un mundo establecido ambiguamente entre las violaciones de las normas sociales y las incertidumbres de la cultura oficial, ya que examina prácticas heterodoxas, especialmente relacionadas con los indígenas.

Palabras clave: Nueva España, México, heterodoxia, género, casta, sexualidad.

\begin{abstract}
:
Engaging primary documents and scholarly debates, this article examines an array of practices in colonial Mexico as it undertakes a discursive account of how gender ideologies informed the politics of discipline and a range of behaviors that went from atypical sexuality to cross-dressing and witchcraft. It speaks to a world set ambiguously between the violations of social norms and the uncertainties of official culture as it examines these heterodox practices, especially those related to Indians.
\end{abstract}

Keywords: New Spain, Mexico, heterodoxy, gender, caste, sexuality.

En 1658, se presentó ante las autoridades de la corte penal de la Ciudad de México una mujer llamada Juana de Herrera, una lavandera mestiza. Herrera les contó que, habiendo salido a lavar la ropa un día en septiembre, unos muchachos corrieron hacia ella. Dando voces, le dijeron que dos hombres estaban "jugando como perros" cerca de la zanja donde ella lavaba la ropa. Ella se acercó un poco para poder ver mejor y pudo observar a dos hombres cometiendo un pecado nefando - un pecado indecible que se refería figurativamente a las relaciones masculinas del mismo sexo, particularmente a la sodomía, entendida como penetración anal (Nesvig 693-694; Sigal, "(Homo)sexual Desire” 5) - . Ambos varones se habían bajado los pantalones, testificó Herrera, y el hombre que estaba arriba había cubierto al de abajo con su capa.

Herrera no se atrevió a acercarse más, por temor a que los hombres la mataran, lo que sugiere que tanto ella como ellos eran conscientes de la represión estatal y eclesiástica que existía con respecto a las relaciones sexuales entre hombres. Juana era, sin embargo, capaz de reconocer al individuo que estaba arriba, a quien identificó como un mulato libre llamado Juan de la Vega.

Posteriormente, las autoridades buscaron a de la Vega en la casa de doña Melchora de Estrada, donde se pensaba que estaba alquilando una habitación. De la Vega ya se había mudado, pero otros inquilinos lo describieron a los investigadores como un mulato afeminado, cuyo apodo era Cotita, sinónimo de mariquita. Describieron cómo de la Vega se ceñía la cintura y usaba un pañuelo sobre su frente del tipo que usaban las mujeres. Además, adornaba las mangas de su corpiño blanco con cintas y se sentaba como mujer en una pequeña plataforma colocada en el suelo, mientras hacía tortillas, lavaba y cocinaba. A de la Vega lo visitaban

Notas de autor

a Autora de correspondencia. Correo electrónico: 1.lewis@soton.ac.uk 
jóvenes, les dijeron a los investigadores, y él se refería a ellos afectuosamente como "mi alma, mi vida, mi corazón”, y se ofendía si no lo llamaban Cotita. Estos compañeros también dormían con de la Vega en su habitación (AGI, México 28, 57B).

La historia de Juan de la Vega terminó trágicamente cuando fue capturado y quemado junto con otros trece hombres acusados de haber cometido el pecado nefando (Gruzinski 255-290). Las leyes ibéricas que lo condenaban habían estado vigentes desde el siglo XIII. Basadas en el código legal medieval conocido como las Siete Partidas, estas leyes condenaban a individuos a muerte por lapidación por incurrir en actos sexuales entre el mismo sexo. La gran mayoría de los así sentenciados eran hombres y la alta tasa de ejecución en España, de las personas identificadas como sodomitas, atestigua la extraordinaria preocupación del Estado y la Iglesia con respecto a las relaciones sexuales entre varones (Greenberg 311-312; véase también Boswell 288-289). Esa tasa se intensificó a finales del siglo XV, cuando se fundó la Inquisición española para enjuiciar a judíos y otros sujetos heterodoxos. En 1497, arder en la hoguera —el destino de Juan de la Vega y los otros - tomó el lugar de la lapidación como el castigo para los sodomitas convictos (Monter 280; Greenberg 302; Gruzinski 263; Nesvig 699; Stavig 142).

La ley española, especialmente bajo la Inquisición, ha sido caracterizada como "bastante represiva" en comparación con otros principios legales en los regímenes de la época (Greenberg 311). Sin embargo, los registros legales de España sugieren que las ejecuciones de sodomitas, al menos por la Inquisición, habían cesado casi por completo a mediados del siglo XVII. En contraste, las ejecuciones de sodomitas por los tribunales seculares, tanto en España como en la Europa protestante, continuaron hasta el siglo XVIII (Monter). Los estudios también muestran que, aunque los sodomitas pasivos — denominados putos en España y en el Nuevo Mundo - eran socialmente desdeñados (Laqueur 53; Boswell 50; Lancaster 242; Nanda 43-56; Paz 39-40), tenían menos probabilidades de ser castigados severamente que los activos, especialmente cuando eran menores de edad o se consideraba que habían sido coaccionados (Nesvig 699; Perry, Genderand Disorder 123; Sigal, "Gendered Power" 103; Stavig 142; Trexler, Sex and Conquest 37, 45; Trexler, Religion in Social Context 585n95). Preocupada por la juventud de muchos acusados, la Inquisición española, a finales del siglo XVI, elevó la edad mínima para la persecución de la sodomía, de los veintiuno a los veinticinco años de edad (Monter 296).

El proceso contra Juan de La Vega sugiere que al menos algunas de las prácticas legales estuvieron presentes en México. Por el momento, no tenemos mucha información sobre los actos sexuales en los que se decía que de la Vega y sus cohortes participaban, pero sabemos por la documentación que de la Vega, al menos, había actuado como el penetrador "activo", y que él y otros hombres tenían relaciones sexuales con muchachos. Mientras que algunos de los condenados en este caso efectivamente fueron designados como pacientes (pasivos), la vida de al menos un muchacho de quince años se salvó - recibió un azote y fue condenado a seis años de trabajos forzados (Nesvig 700) - .

En su ensayo sobre Juan de la Vega y una "ola de represión" mexicana en el siglo XVII contra los "homosexuales", un término que no existía entonces y que sigue siendo problemático (Gruzinski 256, 274; Lancaster 207), el historiador Serge Gruzinski señala que, a diferencia de los indios, judíos, negros y mujeres, tales hombres "continúan molestando", ya que los archivos tienen pocos rastros de sus vidas (256; véase también Nesvig 690). Mi intención aquí no es tanto centrarme en esas vidas, sobre las cuales de hecho tenemos poca información (Sigal, Infamous Desire), sino usar la idea de pecados nefandos de los siglos XVI y XVII para comenzar un recuento discursivo de cómo las ideologías de género permearon tanto las penas o castigos como la promulgación de prácticas heterodoxas, desde comportamientos sexuales atípicos hasta el travestismo y la superstición. Gruzinski comenta sobre las "coincidencias terminológicas" que se sostuvieron entre sodomía e idolatría durante está época (256). En este ensayo contrapongo lo sexual con otros tipos de prácticas sociales, para explorar cómo la indianidad en particular llegó a ser articulada como una pasividad feminizada y a la vez como una fuente de contagios peligrosos. Sugiero que, en la imaginación colonial, los indios encarnaban la paradoja de lo femenino o pasivo, que fue simultáneamente condenada y perdonada, y que también llegó 
"desde abajo" para contaminar el cuerpo político. Tal perspectiva puede ayudar a resolver un conflicto entre Trexler (Religion in Social Context) y Horswell sobre si lo "femenino" en el Nuevo Mundo solo degradaba a los sujetos o si, de hecho, era un constructo que los empoderaba. ¿No podría haber hecho ambas cosas?

Además de procesar sodomitas, las autoridades coloniales buscaban y perseguían la heterodoxia en diversas esferas. Me refiero a estas prácticas y sus expresiones simbólicas, que podríamos definir como lo "grotesco" (grotesque), siguiendo el análisis de Peter Stallybrass y Allon White sobre el carnaval en la Europa moderna. Ese análisis desarrolla la distinción que hace Mikhail Bakhtin entre el ámbito "bajo" de la experiencia humana y el "alto". En el primero, se mapea lo social y corporal como "heterogeneidad, enmascaramiento, protuberante, distensión, desproporción, exorbitancia, clamor, descentrado o arreglos excéntricos $[\mathrm{y}][\ldots]$ necesidades y placeres físicos del 'estrato corporal inferior'", que cuestionan y desestabilizan el propio sistema $(23,56)$. En el segundo ámbito, la legitimidad burguesa de la esfera "alta" y "clásica", constituida por la simetría, lo centrado, la homogeneidad y un creciente racionalismo, se asocia con los grupos socioeconómicos más poderosos (Stallybrass y White 4). Al designar aquello que se considera "alto" también se define aquello que no pertenece a esa categoría y que podríamos considerar como "bajo”, pero que forma parte del mismo sistema. Es decir, para razonar que algo pertenece a un modo superior necesita crear una diferencia con otro, que será denominado como inferior, pero que en realidad no está completamente desligado del primero, puesto que están unidos al mismo mundo. Lo que está “abajo" puede percibirse como "un constituyente primario erotizado de su propia vida de fantasía" (Stallybrass y White 5; traducción propia). ${ }^{1}$

En este estudio tomamos material de códigos legales, así como de procedimientos y consultas de diversas ramas de la judicatura colonial. Aunque los registros se derivan de las fuentes de la Iglesia y el Estado y, por lo tanto, filtran los relatos a través de las mentes y plumas de las élites, son lo más cercano que tenemos para poder comprender las realidades de la gente común, que a menudo se cruzaban con inquisidores, fiscales penales, eclesiásticos y otros ejecutores (Van Young 238). De hecho, sugerimos que el cruce de tales caminos ayuda a profundizar en nuestro entendimiento de los orígenes de ciertas expresiones de lo grotesco. Esto es porque, en el análisis final, el ámbito "bajo" de la experiencia humana en la sociedad colonial probablemente se basó en ambigüedades codificadas en la cultura oficial, especialmente en la cultura religiosa en sí misma. En la parte final de este artículo, llamamos la atención sobre el ritual cristiano, incluyendo el simbolismo de la sangre, la vestimenta sacerdotal y las presuntas prácticas sexuales del clero. La cultura religiosa no solo proporciona pistas sobre lo que era condenado, también proporciona información sobre cómo los indios se convirtieron en sujetos problemáticos cuando se volvieron "pasivos activos" en el corazón del imaginario colonial mexicano.

\section{La feminización de los indios y el enigma de la contaminación}

Estudios recientes sobre la conquista de las Américas han examinado las formas en las que los ideales de género se mapearon en la política y la dinámica social. Dichos estudios prestan especial atención a la construcción subordinada de lo femenino y cómo ambos elementos, subordinación y feminización, llegaron a ser identificados consistentemente con el indio (véase Trexler, Sex and Conquest; Lewis, "The Weakness of Women"; Lewis, Hall of Mirrors; Zamora; Montrose). Como hemos argumentado en Hall of Mirrors, la conquista en sí tenía una dimensión de género y, durante los siguientes siglos, prácticas jurídicas, sociales y religiosas en México se entrelazaron para producir un indio cuyas supuestas incapacidades y vulnerabilidades reflejaban las cualidades que las ideologías de género dominantes les asignaban a las mujeres (Fernández 977). Así, el teólogo español Juan Ginés de Sepúlveda promovió analogías mujeres-indios para defender la legitimidad de la conquista; la lengua de los documentos judiciales coloniales describe a la mujer y al indio con cualidades similares como "débil", "pecador" e "ignorante"; además, las ideologías coloniales negaron tanto a los indios como a las mujeres la plena capacidad de razonar. Las prácticas coloniales confinaban a las 
mujeres a los espacios domésticos y a los indios a los pueblos de su república colonial. Las élites insistieron en la orientación moral de las hembras, que debían supervisar a los varones, y de los indios, que su a su vez monitoreaban a los españoles. Por tanto, la mano de obra colonial estaba constituida por las mujeres subordinadas y los indios productores tanto en el ámbito doméstico como en lo público. Como "menores" legales y dependientes, mujeres e indios fueron, en muchos aspectos, convertidos en niños. También, las hembras eran las brujas por excelencia de la colonia, infectadas con el agente patógeno de la superstición a través del contacto con el diablo.

El ambicioso y controvertido trabajo de Trexler sobre las implicaciones de la cultura sexual ibérica y nativa americana para el discurso y la práctica de la conquista, hace que las cuestiones entrelazadas de género y violencia tengan que ver con la homosexualidad. Argumentando que las subculturas sexuales hombre-hombre existían en ambos contextos y que los iberos y nativos americanos receptores "pasivos" eran más despreciados que los activos, Trexler sostiene que la homosexualidad indígena, especialmente aquella que representa a la figura transgénero y/o travestida del berdache, alimentó entendimientos y discursos ibéricos de la conquista que feminizaron a los nativos del Nuevo Mundo (Sex and Conquest; Nanda). Si bien nuestra intención no es respaldar la posición de Trexler sobre los berdaches como varones degradados que desempeñaban los roles sexuales y sociales de las mujeres, y si bien Trexler ha sido criticado por lo que algunos estudiosos consideran como una separación anacrónica entre activos . pasivos - una separación que tal vez no fue tan clara en la cultura ibérica ni en la cultura indígena americana (Nesvig 690)-, considero que la distinción entre el activo y el pasivo en el ámbito de la sexualidad proporciona pistas convincentes sobre las implicaciones más amplias de actuar o de que alguien actúe sobre otra persona.

Podemos tomar como punto de partida la atención que le da Trexler a la situación paradójica que se produjo en individuos representados como activos en las fuentes, quienes fueron "generalmente admirados o al menos tolerados" por sus roles masculinos como penetradores, siendo castigados más severamente que sus despreciadas parejas pasivas, especialmente en la cultura ibérica (Trexler, Sex and Conquest 35-37, 44-45, 57). Trexler sugiere que esta diferencia puede atribuirse al hecho de que, mientras que los penetrados estaban vinculados a la derrota y a estar "infectados", se consideraba que los penetradores eran la fuente de contagio (Sex and Conquest 146-147). Sostenemos que en la imaginación colonial el diablo tenía un papel "activo" como agente de infección, de manera que los indios feminizados por sus prácticas homosexuales estaban, paradójicamente, también empoderados.

Los discursos coloniales españoles y de la Nueva España estaban llenos de referencias a los peligros planteados por los contagios sociales, que eran presuntamente fomentados por una miríada de actores, cuyas acciones y esencias transgresoras los colocaban fuera del cuerpo social supuestamente sano y funcional. Así, como nos dice Gruzinski, el jefe del juzgado penal, en una carta al rey sobre el caso de Juan de la Vega y sus cohortes, describió los pecados nefandos como una "contaminación [...] cáncer [...] tan generalizada, tan desenfrenada” (Gruzinski 261; AGI, México 28, 57A). En España, en el siglo XVI, como Mary Elizabeth Perry ha escrito, "la homosexualidad masculina parecía tan peligrosa que los hombres acusados de comportamiento homosexual fueron aislados de los demás en la Real Prisión de Sevilla, su desviación era considerada como un contagio que podría infectar fácilmente a otros" (Gender and Disorder 123; traducción propia). ${ }^{2}$ Moros, extranjeros y marineros llegaron a estar particularmente asociados con la sodomía en el Viejo Mundo (Sigal, "Gendered Power” 103; Stavig 142; Nesvig 699; Mott 172-173), donde los moriscos también fueron condenados como "mala hierba" (Root; Boase 9-28). De forma análoga, en el Nuevo Mundo, un virrey describió a los mulatos y negros con el mismo término, "malas hierbas" (AGI, México 27, 52). Las autoridades afirmaban que los vagabundos, en su mayoría no españoles, así como los indios nómadas chichimecas del norte, "infestaban" las carreteras que rodeaban los pueblos coloniales, y ese territorio español debía mantenerse "limpio" de "gente suelta” (AGN, Criminal 369, 2;AGN, General de Parte II, 367; AGN, Reales Cédulas Duplicadas, 3, 7). Mientras tanto, los indios "infectaban" a la población con la brujería que habían recibido del diablo (AGN, Inquisición 360, 31). 
Las mujeres también eran vistas como contaminadoras potenciales. El espíritu español enfatizaba el autocontrol, la "pureza" de los linajes y el honor familiar (Cascardi 237; Franco xiv; Perry, Gender and Disorder 7). El honor se refiere tanto al estado social (que se distingue por la riqueza y la "sangre") como a la preservación de la virtud en forma de virginidad y respeto a la Iglesia, garantizando el carácter de los linajes futuros. En teoría, la sexualidad tanto de hombres como de mujeres estaba sujeta a control (Lavrín 10). Sin embargo, se juzgaba que las hembras eran más emocionales, apasionadas y carnales que los hombres y, por lo tanto, necesitaban la supervisión de varones superiores, como padres, esposos y sacerdotes. Tal supervisión fue pensada para proteger a las mujeres de sus propias tendencias y hacerlas buenas. En realidad, su objetivo era conservar el honor masculino, que podía corromperse por su contacto con hembras fuera de control, quienes contaminaban a los hombres con lujuria, debilidad y enfermedades venéreas (Sánchez-Ortega 197; Perry, "Magdalens and Jezebels"). Aunque las mujeres podían ser devaluadas, también portaban peligros que podían perturbar la jerarquía social.

Para explorar más a fondo el tema del género, y para vincularlo más específicamente a la brujería, podemos recurrir brevemente al Malleus Maleficarum del siglo XV, manifiesto de brujería que, para 1669, había tenido treinta ediciones incluido en alemán, francés e italiano. En este texto, los inquisidores dominicos alemanes Heinrich Kramer y James Sprenger escribieron extensamente sobre los defectos que creían eran constitutivos de la naturaleza femenina. El texto supone tanto una condena de las mujeres como de la superstición, la cual se pensaba que las hembras participaban de manera habitual. El trabajo de Kramer y Sprenger es una diatriba que une a las mujeres "sueltas" con las sexualidades consideradas como perversas y los pecados de las brujas, que se originaron con un diablo seductor que se aprovechó de las debilidades inherentes de las mujeres para imponer su voluntad sobre ellas. El argumento de los dominicos fue retomado por las autoridades coloniales, que creían que las mujeres que se habían liberado de la autoridad de la Iglesia y de sus familiares masculinos caerían naturalmente en una especie de irresponsabilidad que las haría vulnerables a la corrupción del diablo. Para aquellas autoridades, y parece que para gran parte de la población, el demonio convirtió a estas hembras en brujas, y el mismo Lucifer era a quien ellas acudían para llevar a cabo episodios apasionados de relaciones sexuales, tal y como lo recoge la Inquisición. Los peligros para los hombres fueron aclarados por el español Francisco, quien acusó a una mujer mulata de haber tenido relaciones sexuales con el diablo y luego usar sus poderes para hacer de Francisco "no un hombre" (AGN, Inquisición 619, 1).

De manera análoga a las mujeres descritas por Kramer y Sprenger como "sin moderación en bondad o vicio" (42, traducción propia), ${ }^{3}$ los indios podían abrazar al dios español si eran guiados adecuadamente por el clero. Pero, sin tal guía, los indígenas eran tan propensos como las mujeres a ser atraídos por el diablo, un vector no solo relacionado con costumbres sexuales libertinas asociadas con la brujería, sino también con el pecado de la sodomía. De hecho, Bartolomé de Las Casas escribió que los demonios infectaron a indios guatemaltecos con homosexualidad, mientras que Cieza de León identificó al diablo como la fuente de la homosexualidad en la costa del Perú (Trexler, Sex and Conquest 146). Los indios ganaron la reputación de ser los más conocidos de los brujos de la colonia y se convirtieron en los proveedores de los remedios sobrenaturales que otros sujetos buscaban (Lewis, Hall of Mirrors; Cervantes). También fueron descritos por las autoridades religiosas como degenerados sexuales (Motolinía 125, 135; Ortega 38-39; BNAH, Archivo Histórico, 113, 418). El anclaje de la decadencia religiosa y sexual en el mismo mal arroja luz sobre por qué los términos puta y bruja a menudo se encuentran emparejados en historias coloniales mexicanas sobre mujeres descarriadas y por qué, más generalmente, existen "coincidencias terminológicas" (Gruzinski 262-263) que vinculan a las aberraciones sexuales con las religiosas.

Los registros sugieren que la puta, que denota a una mujer excesivamente sexual, y el puto, que señala a un hombre que realiza actos sexuales con otros hombres - pero, en la lengua vernácula, más precisamente un hombre sexualmente pasivo (Trexler, Sex and Conquest 103; Sigal, "(Homo)sexual Desire" 9; Covarrubias Orozco) - , fueron utilizados como insultos en el habla cotidiana. Estos insultos eran a menudo dirigidos a losindios (AGN, Inquisición 316, 40; AGN, Criminal 645, 29; AGN, Criminal 132, 2; AGN, Criminal 
243, 2; AGN, Bienes Nacionales 253, 25; Taylor 81), cuyas supuestas debilidades morales y físicas estaban también combinadas, y cuyos cuerpos se convertían en los objetos de la violencia sexual (AGN, Inquisición 517, 13; AGN, Criminal 109, 20; AGN, Criminal 34, 13; Lewis, Hall of Mirrors). En el caso de Juan de la Vega, tenemos la combinación interesante de los términos puto y puta, dado que la documentación indica que los putos - como algunos de los hombres se referían a sí mismos en el texto- tomaron los nombres de putas notables de la Ciudad de México. Los registros son interesantes, entonces, para ver las formas en las que se une el exceso a las perversiones del orden sexual apropiado, transmitiendo así la sensación de que estos hombres estaban doblemente "fuera de control".

Las actitudes legales españolas, que parecían haber considerado a los penetradores, en los casos de sodomía, más responsables que los penetrados, resonaron en los códigos y prácticas relacionadas con los delitos de brujería, que fueron sorprendentemente indulgentes. En primer lugar, las autoridades coloniales sostuvieron que tanto las mujeres como los indios estaban "cegados" y eran "engañados" por un demonio que tomaba ventaja de su ignorancia. En segundo lugar, mientras que la Inquisición tiene una reputación de brutalidad, tanto las mujeres como los indios eran tratados con una clemencia relativa por este órgano judicial. En España, por ejemplo, no quemaban a las brujas en la hoguera después de principios del siglo XVI. En su mayoría, ellas eran "rehabilitadas" mediante el traslado forzoso a aldeas donde su "reputación desagradable no se conocía" (Henningsen 22; traducción propia). ${ }^{4}$ En la Nueva España, una alta proporción de las acusaciones de brujería no fueron llevadas a juicio, especialmente cuando los acusados eran mujeres o también, en períodos posteriores, cuando la brujería era considerada como una "superstición" nacida de la ignorancia y la falta de "buen sentido" (Alberro, La actividad 86; Alberro, "Herejes, brujas y beatas"; Alberro, Inquisición y sociedad 192; Behar 42; Cervantes cap. 5). Las mujeres a menudo confesaban voluntariamente y sus castigos incluían azotes ocasionales, pero también, especialmente en períodos posteriores, multas, confesiones públicas y humillantes, el exilio temporal y el confinamiento a los espacios femeninos del hogar o la iglesia (Lewis, Hall of Mirrors caps. 2-3; Alberro, Herejes, brujas y beatas; Behar; Cervantes cap. 5).

Además, aunque el sobrenaturalismo indígena, de diversas maneras codificado como idolatría y brujería, fue criminalizado en México y varios indios fueron condenados a muerte por tales delitos a mediados del siglo XVI, en el último cuarto de ese siglo la Inquisición había perdido completamente su autoridad sobre esta población. Los indígenas, en parte, porque eran vistos como "débiles y de poca sustancia", como lo escribió un sacerdote, y, en parte, porque los métodos de la institución eran considerados demasiado duros para estos cristianos nuevos (Klor de Alva 14; Alberro, La actividad 100) quedaron apartados de este sistema de castigo. A diferencia de los negros, los indios habían sido liberados de la esclavitud algunas décadas antes y, como miserableso dependientes, también fueron beneficiados con tutelas especiales de La Corona, que ordenó instituciones y procesos judiciales que facilitaran la equidad entre ellos y los grupos de no indios. En el análisis final, indios degradados y feminizados, que se asociaban rutinariamente con el diablo, al menos en teoría, también estaban protegidos de los alcances más duros de la burocracia colonial.

\section{Dentro de una iglesia en Mérida}

En este momento pasamos a hablar de otro Juan. Juan Ramírez, como Juan de la Vega, era un mulato libre en el México del siglo XVII. Descubierto con otro hombre cerca de una iglesia de Mérida, también fue acusado de un pecado nefando (AGN, Inquisición 498, 16). Mientras que los registros relativos a Juan de la Vega no aclaran quién era su consorte, los concernientes a Ramírez describen a su compañero como un indio. Como discutiré, la narrativa textual contiene elementos de una agresión sexual, feminizando al indígena en relación con el mulato macho, incluso en el contexto de un acto que se consideró como una violación de las normas de género. 
El asunto de Juan de la Vega nos llega a través de informes de funcionarios del tribunal penal y del propio virrey. Por el contrario, el procedimiento contra Ramírez fue escuchado por la Inquisición. La consiguiente riqueza de detalles no hace transparente lo que ocurrió, porque los estratos de significado e interpretación esconden algunos asuntos y revelan otros; en definitiva, la documentación no indica ni culpabilidad ni sentencia. De hecho, el asunto podría haber sido entregado a las autoridades seculares, ya que la Inquisición no tenía autoridad para procesar a los indios por sodomía (Monter 287-288; Alberro, La actividad). Sin embargo, la documentación existente proporciona una visión más profunda de los discursos y del contexto social que interpretaba ciertos comportamientos como actos homosexuales.

El incidente llamó la atención de la Inquisición después de que un indio sacristán llamado Pascual Couoh se encontró con otro indígena, a quien no conocía, pero que más tarde nombró como Andrés Chan, en compañía de Ramírez. Couoh dijo a las autoridades que había encontrado a los dos hombres cometiendo el "pecado nefando" al lado de la iglesia una noche, cuando iba de camino a ver a su propio compañero, otro indio llamado Miguel Tun. En su camino en búsqueda de Tun, Couoh pasó por la casa del sacerdote, que estaba ubicada a un lado de la iglesia. En el corredor que presumiblemente unía los dos edificios, había visto dos formas indistintas (bultos), una encima de la otra. Couoh regresó a su propia casa para buscar una vela y luego volvió para echar otra mirada. En este punto reconoció a uno de los hombres como Ramírez, el otro era Chan, a quien Couoh reconoció como un indio, a pesar de no saber su nombre.

Cuando Couoh se acercó a Ramírez y Chan, el mulato se bajó del indio. Según Couoh, Ramírez se ató los pantalones y se sentó en el parapeto del corredor. Couoh después se dirigió a Ramírez, diciéndole: "Juan, ¿qué estás haciendo aquí? Debes ser mujer, ya que estás con un hombre”. Ramírez respondió que él solo estaba "jugando", momento en el que Chan se levantó e intentó irse. Cuando Tun se acercó al corredor, Couoh le gritó: "Amigo, agarra a ese indio para mí". Tun agarró el poncho de Chan, el cual se rasgó, mientras que Chan y Ramírez corrieron. Couoh se volvió hacia Tun y le preguntó: "Amigo, ¿qué piensas de estos sinvergüenzas, que vienen a hacer sus actos vergonzosos junto a la iglesia?”.

Cuando Ramírez fue llevado ante los inquisidores, testificó que se había reunido con el indio, a quien no conocía, en el patio de la iglesia, donde había ido a descansar después de una visita a una amiga suya, una mulata llamada Gracia. El indio le preguntó a Ramírez de dónde era. Cuando Ramírez respondió que de Campeche, el indio le dijo cuánto él mismo quería ir allí. Ramírez le dijo entonces al indio que lo llevaría y le preguntó de dónde era. El indio respondió que de Valladolid y que en Mérida había trabajado para un hombre que le daba ropa decente durante los días festivos, pero solo para ir a misa, después de lo cual el hombre se llevaba la ropa. El indioentonces extrajo unos pantalones blancos de su camisa y se los dio al mulato, para que los custodiara.

Ramírez les dijo a los inquisidores que había estado con el indio hasta las cuatro de la tarde, momento en que él mismo fue a la iglesia para asistir a misa. Cuando Ramírez regresó, encontró al indio en el mismo lugar y se sentó a su lado. Luego procedieron a charlar sobre Campeche. Después de un rato, el sacristán indio Couoh vino y le preguntó a Ramírez qué estaba haciendo. Ramírez respondió que no estaba haciendo "nada". Cuando Couoh se fue, Ramírez se acostó junto al indio. Como él mismo lo admitió, tocó el pene del indio, pero solo con la intención de agitarlo o molestarlo (alterarlo).

El indio Andrés Chan obviamente había sido atrapado, porque declaró ante los inquisidores el mismo día que su acusador. Cuando le mostraron el pedazo de poncho que había quedado en manos de Tun, Chan dijo que recordaba haberse topado con Tun la noche anterior. Tun estaba borracho, Chan contendió y le dejó tener el poncho para que Tun no lo atacara. Según la versión de los acontecimientos que dio Chan, él había estado durmiendo en el corredor cuando el mulato, a quien también dijo no conocer, llegó y agarró un sombrero que Chan había puesto entre sus piernas. Esto despertó a Chan y él se fue a buscar agua. Cuando volvió, Ramírez comenzó a charlar con él, diciéndole que estaba esperando a unos arrieros que lo iban a acompañar a Campeche. Chan también quería ir y, con la esperanza de conseguir un paseo, se acercó al mulato. De repente, afirmó, el mulato comenzó a pellizcarlo, atizarlo y tocar su "miembro". Chan trató de huir "como hombre", les dijo a los inquisidores, pero, de alguna manera, dos horas después el mulato estaba todavía tocándolo. 
Finalmente, el mulato se fue a comprar tabaco. Cuando regresó, le sugirió a Chan que se mudaran fuera del patio, donde había "demasiado aire", para sentarse en el corredor. Chan lo siguió allí, se acostó y se cubrió con su poncho.

En este punto, el mulato nuevamente comenzó a pellizcarlo y a tocar su pene. Chan le preguntó cómo podía hacer esos "actos vergonzosos" y el mulato le dijo que Chan "no era hombre". El indio respondió: "Sí, lo soy y tengo pene como tư". El mulato entonces acusó a Chan de no ser su amigo porque todos sus amigos "se dejan manosear y registrar todas sus partes". Entonces Chan se alejó del mulato, quien vino tras él y a la vez comenzó a desatarse sus propios pantalones. En este momento llegó Couoh y, cuando Tan se puso a agarrar el poncho de Chan, Chan se escondió detrás de una pared adornada con una cruz en bajorrelieve. El simbolismo del entorno de la iglesia y de la cruz, el subterfugio de Chan y tal vez la presencia de funcionarios machos de la iglesia, no debieron de haber pasado desapercibidos para los inquisidores.

Tomados en conjunto, estos componentes de la narrativa podrían hacer referencia a una cultura eclesiástica que protegía a los indios, especialmente del castigo inquisitorial, pero que pudo haber mantenido a la vez una subcultura homoerótica, incluso cuando castigaba la sodomía. Por ahora, dejamos ese tema a un lado y observamos que, si bien no sabemos el resultado de este caso en particular, podemos estar bastante seguros de que el indio fue liberado. Este resultado estaría en consonancia con las actitudes de la Iglesia y el Estado hacia los indios, quienes, como ya he señalado, eran dependientes y no estaban bajo la jurisdicción de la Inquisición. También podría haber sido consecuencia de las actitudes hacia los pasivos en los encuentros homosexuales si, como hemos planteado, estos eran castigados de manera más moderada que los activos por ser frecuentemente jóvenes y/o porque se entendía que habían sido coaccionados. Además, los mulatos estaban sujetos a la Inquisición y se pensaba en general que eran "agresivos" y que probablemente tiranizaban a los indios.

Tanto si Chan permitió que el mulato lo montara, y fue por lo tanto el "paciente" (el participante pasivo) como el indio sacristán Couoh les dijo a los inquisidores-, como si Chan simplemente estaba molesto porque el mulato tocó sus genitales, la narrativa textual presenta claramente a Chan como la "víctima", mientras que retrata al mulato Ramírez como el agresor. Sin embargo, una amiga de Ramírez, llamada Gracia, también les dijo a los inquisidores que el mulato había ido a hacer la compra para una mujer a la que ayudaba en las tareas domésticas; también dijo que él cocinaba, molía el maíz, lavaba y almidonaba la ropa, y hacia chocolate todas tareas propias de una mujer-.

Sin duda, hay una dimensión de casta en este encuentro. Como he mostrado en otra parte (Lewis, Hall of Mirrors cap. 3), y como he dicho anteriormente, los indioseran a menudo representados como las víctimas de la agresión mulata, incluso cuando eran reconocidos como los más poderosos practicantes de la brujería. En el caso que acabamos de revisar, los detalles de las afiliaciones y prácticas sociales del mulato hablaban - como en el caso de Juan de la Vega - de las cualidades femeninas del acusado. Pero, con respecto al acto sexual real descrito - que se menciona de manera diversa en una elaborada polinización cruzada de términos y conceptos como un acto diabólico, un pecado "indecible", un crimen de sumisión y un pecado contra la naturaleza-, el indio Chan emerge como el más feminizado de los dos, porque él era el que estaba abajo.

Dado lo que se puede discernir acerca de las actitudes oficiales hacia los indios, no sería difícil leer el relato de Chan, sobre su encuentro con el mulato en Mérida, como un discurso estratégico que conscientemente invoca ideas coloniales sobre los indios y sobre las relaciones entre los indios y otras castas. Realmente no tenemos manera de saber la verdad. Sin embargo, la narrativa del texto feminiza al indio para convertirlo en la víctima de la agresión del mulato, ya que de nuevo apunta al tema de la seducción. En sus sentidos sexuales y más generales, la seducción es fundamental para entender la cadena de "contaminación” y, por lo tanto, los peligros latentes de la indianidad feminizada. De hecho, era precisamente su debilidad o pasividad la que unía a los indios y a las mujeres con el sacrilegio (Franco xiii; Silverblatt 161). Como las cualidades asignadas a algunos actores en encuentros de personas del mismo sexo, quienes podrían haber sido jóvenes y quienes se entregaron a un "agresor", la pasividad subraya la falta de convicción que puede llevar a la coacción. Esto ayuda a explicar no solo por qué los pasivos en actos sexuales entre hombres podrían haber sido más desdeñados que 
los activos, sino también por qué habrían sido castigados con menor severidad. Las mujeres y los niños, aunque estuvieran involucrados en comportamientos prohibidos, al igual que los indios, no eran responsabilizados por los actos que los contaminaban. De esta manera, el indio Chan, incluso cuando admitió permanecer en la compañía del mulato voluntariamente durante horas, sostuvo de manera clara en su declaración que Ramírez había hecho avances sexuales de los que él fue víctima.

\section{Enmascarado en secreto}

Aunque Juan Ramírez no es travestido, como Juan de la Vega, se dedica a tareas domésticas propias de la mujer. Trexler asocia el travestismo y las prácticas femeninas con los pasivos (Trexler, Sex and Conquest 134-135). Pero claramente esta asociación no se sostenía en el caso de De la Vega, un mulato que se vestía y actuaba como un "pasivo", aunque también fue visto montando a otro hombre. Tampoco se sostenía para el mulato Ramírez, cuyo caso, como el de De la Vega, es de interés en este respecto porque la narrativa expone de nuevo una combinación anómala. De acuerdo con las afirmaciones de Trexler, un hombre afeminado y también penetrador propone una combinación que podría estar conectada con la agresión que las autoridades coloniales les atribuían a los mulatos. También vuelve a exponer los límites de lo que sabemos sobre la "homosexualidad" y las identidades de género y casta en la Nueva España.

La atención pública se dirigía a varones como De la Vega y Ramírez, puesto que a las relaciones desarrolladas entre "hombres vistiéndose y actuando como mujeres" se les atribuía cierta "lascivia" (Greenberg 295; Perry, Gender and Disorder 124, 133). Fueran cuales fueran sus comportamientos reales, debido a la disonancia entre la ropa, la conducta social y el sexo, estas personas estaban marcadas con lo que Marjorie Garber describe como la "inestabilidad de identidades sobre las cuales se desarrollaron las estructuras y jerarquías sociales" (223; traducción propia). ${ }^{5}$ Sin embargo, "actuar como una mujer" y el travestismo no eran castigados en sí mismos con la muerte. Como Trexler escribe sobre este tema, "las leyes contra el travestismo a menudo no se tomaban en serio [...] [y] los europeos tradicionales en general, estaban mucho más dispuestos a pensar en el travestismo como un producto normal de intercambio social" (Sex and Conquest 142; traducción propia). ${ }^{6}$ Sin embargo, sin sugerir, por ejemplo, que las vidas de De la Vega y sus cohortes travestidos se habrían salvado si "hubieran parecido" hombres, ciertamente parece que la cuestión del vestido era fundamental de acuerdo con las preocupaciones de las autoridades que los persiguieron y los mataron. De hecho, gran parte de la narrativa del caso de De la Vega se centra no tanto en los detalles de sus prácticas sexuales y las de los demás, sino en qué tipo de ropa usaban típicamente, por significar esa ropa formas más profundas de desviación.

A este respecto, las mujeres travestis también llamaban la atención. Sin embargo, aunque violaban clara y explícitamente las normas de género, ellas no se asociaban con actos sexuales entre personas del mismo sexo, a diferencia de los hombres travestis a los que se les atribuía la práctica de la sodomía. De hecho, hasta el siglo XVIII, cuando el papel de la sáfica, una mujer que prefería parejas sexuales femeninas, emergió en el discurso europeo, las prácticas sexuales entre personas del mismo sexo rara vez se asociaban con mujeres (Greenberg 306, 310-311; Perry, Gender and Disorder 123; Nanda 87-88). Cuando así sucedía, no eran definidas como sodomía, lo que generalmente significaba penetración anal con un pene (Nesvig 694). Las mujeres que conocemos de la España y del Nuevo Mundo de los siglos XVI y XVII o tenían relaciones sexuales con hombres o afirmaban ser virginales. Por una parte, su comportamiento sexual no negaba aquellos códigos morales que cultivan la heterosexualidad. Por otra parte, las mujeres travestidas podrían haber generado menos condena que los hombres travestidos, porque la "masculinidad" era el ideal español más valorado. Por lo tanto, las mujeres que se vestían como hombres podrían haber sido más toleradas por las autoridades que los varones que expresaban su feminidad a través del vestido y, por lo tanto, libremente elegían limitar su poder social (Perry, Genderand Disorder 127-136). 
Un buen ejemplo de una mujer que se travistió y fue tolerada por las autoridades, y uno de los pocos ejemplos que de hecho existen, es el de la monja española Catalina de Erauso. Por decir que era mujer "virtuosa" y una virgen comprobada, la corona española le otorgó una licencia real para ponerse ropa de hombre en el siglo XVI. Vestida como soldado, viajó a lo largo del Nuevo Mundo, incluyendo México (Perry, Gender and Disorder 133-134).

Y luego tenemos a Úrsula de Las Vírgenes, una viuda española y residente de la Ciudad de México, que también se vestía con ropa de hombre para escapar de los confines de la domesticidad. Fue llamada ante las autoridades eclesiásticas a finales del siglo XVII, por lo que describieron como su "estilo de vida desordenado". En primer lugar, su hábito desconcertante de vestirse con ropa de hombre, especialmente durante la Cuaresma, la sometió a la censura. En segundo lugar - y esto explicaría el interés eclesiástico en su caso- de Las Vírgenes se ponía no solo ropa masculina, sino también vestimenta religiosa exclusiva del varón, que se describe en el texto como "una túnica de penitencia con su capirote". Vestida de monje, tenía la costumbre de andar por la ciudad y entrar en las casas de la gente. Como la casada española Agustina Rodríguez informó a las autoridades, de Las Vírgenes se movía "con confianza” mientras vestía ropa de hombre. Esta indicación nos parece bastante sutil, ya que nos imaginamos la insolencia con la que de Las Vírgenes llevaba a cabo su subterfugio indecente, al menos en público. Otros alegatos vinieron de los propios criados de De Las Vírgenes, incluyendo el de una mestiza llamada Cathalina, quien aparentemente le dijo a Agustina Rodríguez que Úrsula a menudo se vestía como hombre para salir a la calle por la noche. Y otro testigo español reclamó que incluso cuando el marido de De Las Vírgenes se estaba muriendo, ella se ponía ropa para ir a donde quería cuando caía la oscuridad (AGN, Bienes Nacionales 596, 20). De las Vírgenes por lo tanto se aventuraba en espacios públicos codificados como masculinos - las calles de la ciudad por la noche -, mientras que, como hemos visto, ambos Juanes se quedaban en casa para hacer tortillas.

De Las Vírgenes fue retratada como ruidosa y traficante de rumores. Ella ciertamente no era un cuerpo virginal, ya que andaba "ilícitamente" con hombres. Esto habla del tipo de lascivia atribuido a varones como de la Vega, los "putos" que se dedicaban a actos homosexuales. Además, las mujeres como Erauso y de Las Vírgenes, que vestían ropa de hombre, lo hacían en conjunto con comportamientos masculinizados que les daban movilidad y libertad, apartándose de los límites domésticos del hogar y de la Iglesia atribuidos a las mujeres. Así, al igual que sus homólogos masculinos, tales hembras atrajeron sospechas porque violaban las coordenadas espaciales y temporales en las que se movían los cuerpos "legítimos". Sin embargo, estas mujeres no violaron las normas heterosexuales básicas de la conducta sexual en sí.

Las reglas generales sartoriales de los principios del mundo moderno, incluyendo las de México, fueron diseñadas para facilitar lo que Garber llama legibilidad cultural .cultural legibility) (25), pero no solo con respecto a los códigos de género. En México, las estipulaciones legales en cuanto a la vestimenta también se aplicaban a la casta, y mucha actividad legal tuvo lugar alrededor de la implementación y disputa de los códigos referentes a este tema. Presumiblemente, las normas de vestimenta no tenían que ser dictadas cuando se trataba de género, porque tales normas estaban codificadas en la Biblia misma. Las violaciones, entonces, eran mucho mayores que las provocadas por los estatutos de casta.

La categoría de ropa que incluye capas, chales y mantas es de particular interés porque habla de las incertidumbres de género y casta, al mismo tiempo que difumina la división entre lo secular y lo sagrado. Así, a los españoles se les permitía usar un tipo de capa y a los indios otro. Los hombres se ponían mantos, las mujeres usaban mantas y chales; los hombres no usaban faldas, pero las mujeres sí lo hacían; y los monjes llevaban un tipo particular de prenda larga llamada hábito. Este tipo de vestuario parece haber jugado un papel central en el subterfugio del género y la casta. Por ejemplo, Horswell, tras consultar un ritual indígena en una plantación, representado por el cronista andino colonial Guaman Poma, así como otros relatos etnográficos contemporáneos, relaciona los chales de mujeres usados por practicantes rituales masculinos con la "subjetividad del tercer género" (third gender subjectivity) y la mediación de "opuestos de género absolutos" (absolute gender opposites) (37-40). En su trabajo sobre el género y el adorno sartorial de estatuas 
religiosas en España, Italia y el Nuevo Mundo, Trexler también se refiere a capas y túnicas —particularmente a la vestimenta de los sacerdotes y de la Virgen María - como "sexualmente neutrales" o "unisexuales" (392, 399, 399n97). Garber hace la observación más amplia de que los "cuerpos ocultos bajo las túnicas son objeto de sospecha" $(220)^{7}$ y la documentación colonial sobre el vestido cruzado a menudo incluye referencias a prendas largas que conllevan actos mágicos y carnavalescos, usualmente con un toque sexual. Juan de la Vega, por ejemplo, usó su capa para cubrir a su compañero y su propio cuerpo y así "escondió" a ambos durante el acto sexual. De otro modo, se describía también como sartoriamente femenino. Otro de los hombres condenados con él, un mestizo de setenta años, bailaba con otros hombres con la capa atada alrededor de la cintura (Gruzinski 272-273).

Ciertamente, Úrsula de Las Vírgenes, vagando por las calles vestida con una túnica de monje, nos habla de la indefinición útil y la fluidez simbólica que los ropajes ocultan. Lo mismo ocurre con las acciones de un panadero en la Ciudad de México del siglo XVII. Él usaba ropa similar a la de Las Vírgenes para inventar una nueva persona para su esclavo, violando así una serie de límites categóricos. En concreto, usaba una túnica larga "como la de los monjes" para castigar al esclavo, a quien acusó de rebelarse. Vistiéndole con la túnica, el panadero lo hizo desfilar en la plaza pública frente a la catedral de la Ciudad de México. Para mejorar su mensaje, el panadero transformó los otros signos corporales del esclavo al moldear su cabello con la tonsura de un monje y blanquear su rostro con harina. Las autoridades pensaban que estaba mostrando desprecio por el clero, pero el panadero explicó que estaba más bien castigando y "avergonzando" al esclavo (AGN, Bienes Nacionales 732, 2).

Claramente, tanto los significados religiosos como los de casta — porque, poniendo el blanqueamiento de la cara del criado a un lado, los monjes eran, por definición, españoles - informan el intento del panadero de deshonrar a su esclavo. Una vez más, esos significados parecen estar codificados en una prenda larga. Además, también se podría leer una feminización latente en las acciones del panadero, porque no solo disfrazó a su esclavo como un monje asexual, y por lo tanto no masculino, sino que también, como les dijo a las autoridades, formó la prenda con ropa vieja de su esposa. Él, por lo tanto, transformó directamente las faldas de una mujer en la sotana de un hombre.

\section{El diablo y el indio: vestirse para el éxito}

Hasta ahora hemos sugerido que los indios eran feminizados, "infectados" con contaminantes que venían del diablo y que la ropa era un punto focal simbólico para una variedad de heterodoxias. Queda ahora unir estas diversas cuestiones. Comienzo con el relato de un demonio nombrado Mantelillos que se convirtió en el compañero de un vaquero mestizo llamado Juan Luis. Cuando se le apareció por primera vez a Juan Luis, Mantelillos llevaba una capa impermeable (aguadera). Sucedió que también tenía dos caras, que Juan Luis le pidió que no exhibiera en encuentros futuros porque le molestaban. Juan Luis les dijo a los inquisidores que adoraba a ese demonio "como a Dios" y que se arrodillaba ante él para pedirle ayuda.

El nombre Mantelillos, que también se le adjudica al diablo en otro ejemplo (AGN, Inquisición 276, 2) es un rompecabezas. Nunca hemos encontrado una traducción en los textos, aunque los inquisidores a menudo les pedían a los acusados y testigos que explicaran términos poco familiares. Esto sugiere que lo que significaba "Mantelillos" era entendido, por lo menos, por los mexicanos de los siglos XVI y XVII. Solo podemos especular aquí, pero creo que el apodo podría haber derivado de un manto (una capa de hombre) o una manta (un chal de mujer) o, lo más probable, de un mantel, una tela de altar. El nombre del diablo, entonces, podría haber significado algo así como 'mantel pequeño de altar', y Mantelillos se vestía con capa cuando Juan Luis lo encontró por primera vez (véase también Trexler, Religion in Social Context 380). Por lo tanto, de nuevo vemos prendas largas y codificadas (tanto la que llevaba Mantelillos como la que probablemente informó su 
nombre) que tienen un papel significativo en la promulgación de la heterodoxia. Esta vez, tales prendas están vinculadas a un demonio con un rostro inestable.

El documento también presenta una conexión entre la figura encapuchada del demonio y un indio, porque en el transcurso de lo que fue una larga prueba de la Inquisición, Juan Luis admitió que un indígena le había presentado a Mantelillos. Los inquisidores consideraron que el papel del indio era tan central que interrogaron a Juan Luis sobre quién era, en dónde lo había conocido y si Juan Luis se había "atrevido" en algún momento a llamar al mismo diablo sin la intervención del indio. Cuando el indígena fue cuestionado por los inquisidores, admitió que él y sus antepasados habían aprendido todo lo que sabían del diablo (AGN, Inquisición 147, 6).

Otro indio que estaba en términos íntimos con el diablo acudió en ayuda de la esclava mulata Antonia que vivía en los confines del norte del territorio español a finales del siglo XVII. Como hemos discutido extensamente en Hall of Mirrors (cap. 7; Deeds), la esclava, usando "hierbas y polvos" suministrados por el indígena, escapó de la casa de su amo y se vistió de hombre. Aunque la ropa no está descrita en detalle, en su disfraz mágico, la mulata mantenía su identidad masculina con la ayuda de los remedios del indio, que ella frota por todo su cuerpo mientras "llama e invoca al diablo para que la ayude". El diablo hacía todo lo que ella ordenaba y con su ayuda era capaz de participar en actividades codificadas como masculinas, incluyendo torear y dominar caballos mientras ella "servía a amos diferentes como vaquero" (AGN, Inquisición 525, 48).

Antonia se cuidó de explicar a las autoridades, a quienes finalmente se entregó, que ninguno de los hombres con los que tuvo contacto había descubierto que ella era mujer. De hecho, nunca había tenido "ilícitas amistades" con sus acompañantes masculinos. La implicación, por supuesto, era que la joven había permanecido pura en sus interacciones con los hombres a pesar de sus transmutaciones sartoriales y de género, y que su ropa no solo transformó su género, sino que también le permitió mantener el engaño.

Antonia continuó diciéndoles a los inquisidores que una noche se despertó y se encontró volando por el aire hacia una montaña. Cuando amaneció, vio una figura masculina vestida en un hábito (ábito) oscuro con una hoja de palma en su mano y un corte de pelo "como el de un sacerdote". Ella lo siguió por la montaña y cuando él desapareció, la esclava se fue a confesar. Era San Antonio, dijo, y supo que era él porque el día anterior había pedido su ayuda.

Que la mulata se entregara después de ver una aparición de San Antonio bañado en luz habla de las indeterminaciones de las formas corporales en este entorno colonial: el cuerpo del santo también podría leerse como un reflejo del diablo que, según la joven, era un hombre blanco, el cual desapareció en cuanto San Antonio se materializó. Siguiendo las ideas de Stallybrass y White sobre lo carnavalesco, podríamos ver el viaje de Antonia como un "bricolaje de fantasía" (fantasybricolage) (182) que desestabiliza las posiciones sociales dadas e "interroga las reglas de inclusión, exclusión y dominación que estructuraban el conjunto social" (44). ${ }^{8}$ Al final, Antonia reafirmó las normas oficiales al quitarse su vestido masculino, renunciar a su libertad y a su compañero indio, y entregarse a unos hombres blancos: el santo, sacerdotes, inquisidores, españoles y, por último, los amos. Todos ellos tenían el poder de "curar" sus transgresiones corporales. Estos varones contrastan con el diablo, que, por supuesto, le fue presentado a Antonia por un indio que ya había sido "seducido".

\section{Altos y bajos: la política del "grotesco" y el pasivo activo}

En la Nueva España, los indios fueron el prisma simbólico a través del cual el cuerpo grotesco —el “bajo”, el antitético- llegó a ser entendido como corruptor del orden social. Encarnando lo femenino, losindios pasivos fueron manipulados; teólogos como Las Casas habían acusado a los propios conquistadores de corromperlos moralmente y hasta de masacrarlos. Los indios, al ser los receptores de un contagio descargado por el diablo, estaban entre los más activos de los sujetos coloniales y eran considerados como una fuente tanto de brujería como de sodomía; podríamos decir que los indios procedían "activamente" a contaminar el cuerpo social colonial. Así, aun cuando el "alto" era amenazado con la "ferocidad" del bajo (Stallybrass y White 147), 
también informaba con este discurso acerca de cómo el inferior había sido producido desde los estamentos superiores, porque el diablo era una invención europea.

Entre las muchas facetas de la historia de Antonia que vale la pena explorar, se destaca su demonio, que le ofrece ayuda una vez que se libera de la esclavitud gracias al indio, quien hace posible su vestimenta masculina "mágica" para trabajar. Este diablo se metamorfosea en San Antonio cuando ella está lista para entregarse. El parecido entre su propio nombre y el del santo no debe pasar desapercibido y tampoco el hecho de que San Antonio se le aparece en una montaña bañada en luz, creando una imagen muy parecida a la transfiguración de Cristo. Esta asociación recuerda lo que Alison Weber ha escrito sobre Magdalena de la Cruz, una la monja española del siglo XVI, quien testificó ante la Inquisición sobre una visión beatífica de Cristo que se transmuta en un diablo $(173,176)$. Todas estas amalgamas - el caso de Antonia que yuxtapone al diablo y a un santo semejante a Cristo; la aparición del demonio Mantelillos, quien tomó su nombre de la tela de un altar; y las visiones de una bruja mulata que supuestamente confundió la figura de un sacerdote con la de un demonio que, según ella, estaba escondido detrás de un altar (AGN, Inquisición 439, 14) - nos hablan directamente de las relaciones entre lo bajo y lo alto que estamos desenredando aquí.

Las imágenes religiosas a menudo inundan los cuentos mexicanos coloniales de transgresiones, y los procedimientos por brujería están repletos de referencias a oraciones sacrílegas y azotes de figuras de Cristo. En este sentido, llamamos la atención sobre la sangre, una sustancia ambigua que era simultáneamente santa y sacrílega, neutral y contaminada. Por ejemplo, la sangre de un pinchazo en el dedo de una mujer española era solicitada por un sirviente de un demonio, el cual identificó a una mujer india como su hija y dijo que poseía un pene "tan grande como un palo" "Mi amo llora por ti", le dijo el sirviente a la mujer, amenazándola con la muerte si no cumplía, "dame un poco de sangre de tu brazo, tengo que tomarla y dársela [a él]" (AGN, Inquisición 218,4$)$. A veces, la sangre era la tinta con la que se inscribían las palabras del maligno en los "libros del diablo", que deben de haber sido tan ininteligibles para las personas no alfabetizadas como la Biblia que usaban los eclesiásticos (véase también Taussig 259, 264). Las partes inferiores —la "suciedad" y lo "vulgar" - a través de las cuales se constituía lo bajo y sobre las cuales se centraban las transgresiones sexuales, eran también la fuente de la sangre menstrual con la que innumerables mujeres coloniales de todas las castas adulteraban la comida y la bebida para domesticar a sus amantes descarriados. Un médico testificó ante la Inquisición que tal sangre era normalmente inofensiva. Pero también podría ser un camino para la encarnación de la infección, si la persona de cuyo cuerpo procede está enferma o si ese individuo había entrado en un pacto con el diablo (AGN, Inquisición 442, 33).

Solicitada por el demonio, la sangre era una sinécdoque para el parentesco, así como un signo de lealtad. En términos más generales, la sangre simbolizaba la transferencia de la potencia del diablo al cuerpo de la persona que la proporcionaba. Este es el mismo efecto que proveía la sangre de Cristo, que, junto con su carne, se decía que alimentaba a las almas de los creyentes. En la Nueva España, donde la conversión era un objetivo principal de la conquista y donde circulaban ampliamente monjes y sacerdotes, los eclesiásticos les enseñaron a aquellos a su cargo, incluidos los indios y los esclavos africanos, a comulgar con Cristo al beber su sangre.

La sangre no fue el único punto focal simbólico en el núcleo del imaginario colonial mexicano, donde lo bajo y lo alto, lo grotesco y lo clásico, lo femenino y lo masculino, y lo profano y lo sagrado se reunieron y mezclaron. Como hemos visto, la ropa daba cabida a sus propias discordancias, especialmente cuando cubría cuerpos y estaba acoplada con las sexualidades heterodoxas, como a menudo parecía suceder. Las ambigüedades sartoriales y corporales a veces se exhibían a través de la vestimenta religiosa, como las túnicas de monjes, que Garber identifica como “invitaciones” especiales para la parodia y el cruce de género, y, por lo tanto, excepcionalmente desafiantes para las convenciones del "género sartorial" (sartorial gender) en la historia occidental (212). Las imágenes de brujas y demonios con las que estamos familiarizados — que se centran en túnicas fluidas-, de hecho, nos recuerdan lo que podría haber usado un monje del siglo XVI. Más sorprendente aún es una ilustración moderna de una hechicera vasca inspirada por los escritos del cazador de 
brujas Pierre de Lancre, de principios del siglo XVII, quien muestra a una mujer joven que está completamente desnuda, pero cuyo cabello está recortado en la forma de la tonsura de un monje.

Las transgresiones corporales simultáneamente ocultas y significadas por prendas sueltas también se podían encontrar entre los miembros del clero que, aunque estaban obligados por los juramentos del celibato, constituían un colectivo en el que "la sodomía fue ampliamente practicada", al menos según el capellán jesuita español del siglo XVI Pedro de León (Boswell 188; Greenberg 285-286, 290). Como ha escrito Trexler, en los espacios de clausura de los monasterios, el contacto hombre-hombre era la norma y los jóvenes novatos estaban subordinados a "padres-monjes y frailes en un ambiente masculino, una subordinación que a menudo tenía un componente sexual" (Trexler, Sex and Conquest 3; Sigal, "(Homo)sexual Desire" 15). ${ }^{10}$ Incluso cuando la Iglesia misma se empezó a preocupar por sofocar la sodomía y otras prácticas sexuales entre el clero (Greenberg 312), la atmósfera sexual de la vida del monasterio podría haber influido en cómo los religiosos veían estas prácticas en los indios, negros, mulatos y mestizos, entre quienes los eclesiásticos extendían la conquista (Trexler, Sex and Conquest 3). De hecho, podríamos preguntarnos a este respecto si el indio Juan Zurrador, uno de los varones atrapados en la ola de represión que arrastró al mulato Juan de la Vega, había reunido a una serie de hombres y niños para una simultánea celebración de San Nicolás y pecados nefandos porque estaba confundido o porque sus acciones tenían un tipo de claridad históricamente específica. Y entonces, ¿qué tipo de compañero era Miguel Tun para el sacristán indio Pascual Couoh?

Reuniendo una variedad de lo "grotesco" con una diversidad de actores, hemos propuesto una discusión sobre las formas en las que las prácticas corporales indexaban lo bajo —-desde la sodomía hasta el travestismo y la superstición - - y hablaban del entendimiento de un mundo vivido, que fue establecido ambiguamente entre violaciones de normas sociales e incertidumbres codificadas en general en la cultura misma, y específicamente en la cultura religiosa. En la Nueva España, los espacios inestables que los demonios dominaban eran consistentemente bañados con imágenes religiosas como un conjunto fértil de símbolos y actos fluidos y burlescos que se propagaron con los españoles a lo largo del territorio. Así, si la doctrina católica "formó la conciencia popular", ${ }_{11}$ como David Greenberg ha observado de Europa en la Edad Media (291), en la Nueva España parece haber fomentado no solo ideas en evolución de lo que era respetable, sino también muestras explosivas de actividades "bajas" e interconectadas. En conjunto, las asociaciones que hemos hecho sugieren que esas actividades tenían en común no solo su condena oficial como abominaciones, sino también las formas similares en las que se basaban en imágenes, discursos y relaciones sociales que eran simultáneamente bajas y altas (véanse también Trexler, Sex and Conquest 146-147; Greenberg 294-295; Garber 26-28).

En el análisis final, los contagios sexuales y sobrenaturales más virulentos en la Nueva España se pueden identificar con las figuras yuxtapuestas de las élites religiosas y sus diabólicos doppelgängers. Todas estas figuras - sagradas y profanas - tenían relaciones especiales con los indios neófitos a los que subordinaban de acuerdo con sus propios objetivos. Por lo tanto, las "ansiedades" provocadas por las maneras resbaladizas en las que el vestido y otras prácticas corporales violatorias se desarrollaban en la Nueva España apuntaban no tanto a la "disolución de las fronteras" (dissolutionof boundaries) en tiempos de cambio social —como Garber ha sostenido, por el travestismo y sus estados corporales asociados en la Europa moderna temprana (24-25) -, sino a los deseos de las élites de contener y definir el deslizamiento dentro de los regímenes particulares de autoridad. Estas prácticas imitaron la ambivalencia codificada en el vestido, la sexualidad y lo sobrenatural tal y como se encuentran en el ritual católico, y, por consiguiente, parecen no ser tanto transgresiones desapegadas y desafiantes, sino un conjunto de metáforas sublimadas por la "alta" cultura. Esa cultura, que protegía a losindios como "menores" legales bajo el dominio de la corona española (Lewis, Hall of Mirrors 18-19, 52-53) y que a la vez los imbuía con poderes diabólicos desestabilizadores, revela múltiples sospechas en torno a cómo y hasta qué punto el pasivo podía, de hecho, penetrar el cuerpo político colonial. Además, no por casualidad, nos sugiere la existencia de un espacio híbrido colonial que simultáneamente desprestigia y empodera a lo femenino. 


\section{Referencias}

Archivo General de Indias (AGI), México 27, 52, 1608.

Archivo General de Indias (AGI), México 28, 57A, 1658.

Archivo General de Indias (AGI), México 28, 57B, 1658.

Archivo General de la Nación (AGN), Bienes Nacionales 253, 25, 1604.

Archivo General de la Nación (AGN), Bienes Nacionales 596, 20, 1684.

Archivo General de la Nación (AGN), Bienes Nacionales 732, 2, 1605.

Archivo General de la Nación (AGN), Criminal 369, 2, 1661.

Archivo General de la Nación (AGN), Criminal 645, 29, 1578.

Archivo General de la Nación (AGN), Criminal 132, 2, 1647.

Archivo General de la Nación (AGN), Criminal 243, 2, 1643.

Archivo General de la Nación (AGN), Criminal 109, 20, 1683.

Archivo General de la Nación (AGN), Criminal 34, 13, 1639.

Archivo General de la Nación (AGN), General de Parte II, 367, 1663.

Archivo General de la Nación (AGN), Inquisición 360, 31, 1627.

Archivo General de la Nación (AGN), Inquisición 619, 1, 1672.

Archivo General de la Nación (AGN), Inquisición 316, 40, 1617.

Archivo General de la Nación (AGN), Inquisición 517, 13, 1674.

Archivo General de la Nación (AGN), Inquisición 498, 16, 1691.

Archivo General de la Nación (AGN), Inquisición 276, 2, 1605.

Archivo General de la Nación (AGN), Inquisición 147, 6, 1595.

Archivo General de la Nación (AGN), Inquisición 525, 48, 1691.

Archivo General de la Nación (AGN), Inquisición 439, 14, 1656.

Archivo General de la Nación (AGN), Inquisición 218, 4, 1598.

Archivo General de la Nación (AGN), Inquisición 442, 33, 1652.

Archivo General de la Nación (AGN), Reales Cédulas Duplicadas 3, 7, 1587.

Alberro, Solange. "Herejes, brujas y beatas: mujeres ante el tribunal del Santo Oficio de la Inquisición en la Nueva España”. Presencia y transparencia: la mujer en la historia de México, editado por Carmen Ramos-Escandón, El Colegio de México, 1987, pp. 79-94.

---. Inquisición y Sociedad en México, 1571-1700. Fondo de Cultura Económica, 1988.

---. La actividad del Santo Oficio de la Inquisición en Nueva España, 1571-1700. Instituto Nacional de Antropología e Historia, Investigaciones Históricas, 1981.

Behar, Ruth. "Sex and Sin, Witchcraft and the Devil in Late-Colonial Mexico". American Ethnologist, vol. 14, n. ${ }^{\circ}$ 1, 1987, pp. 34-54.

Biblioteca Nacional de Antropología e Historia (BNAH), Archivo Histórico 113, 418, 1554.

Boase, Roger. "The Morisco Expulsion and Diaspora: An Example of Racial and Religious Intolerance”. Cultures in Contact in Medieval Spain, editado por David Hook y Barry Taylor, Kings College, 1990, pp. 9-28.

Boswell, John. Christianity, Social Tolerance, and Homosexuality. University of Chicago Press, 1980.

Cascardi, Anthony J. "The Subject of Control". Culture and Control in Counter-Reformation Spain, editado por Anne J. Cruz y Mary Elizabeth Perry, University of Minnesota Press, 1992, pp. 231-254.

Cervantes, Fernando. The Devil in the New World. Yale University Press, 1994.

Covarrubias Orozco, Sebastián de. Tesoro de la lengua castellana o española. 1611. 1984. 
Deeds, Susan M. "Brujería, género e inquisición en Nueva Vizcaya”. Desacatos: Revista de antropología social, n. ${ }^{\circ}$ 10, otoño-invierno de 2002, pp. 30-47.

Fernández, James D. "The Bonds of Patrimony: Cervantes and the New World”. Papers of the Modern Language Association, vol. 109, n. ${ }^{\circ}$ 5, 1994, pp. 969-981.

Franco, Jean. Plotting Women: Gender and Representation in Mexico. Columbia University Press, 1989.

Garber, Marjorie. Vested Interests: Cross-Dressing and Cultural Anxiety. Routledge, 1992.

Greenberg, David F. The Construction of Homosexuality. University of Chicago Press, 1988.

Gruzinski, Serge. "Las cenizas del deseo: homosexuales novohispanos a mediados del siglo XVII". De la santidad a la perversión, o de porqué no se cumplía la ley de Dios en la sociedad novohispana, editado por Sergio Ortega, Grijalbo, 1986, pp. 255-290.

Henningsen, Gustav. The Witches' Advocate: Basque Witchcraft and the Spanish Inquisition (1609-1614). University of Nevada Press, 1980.

Horswell, Michael. "Toward an Andean Theory of Ritual Same-Sex Sexuality and Third-Gender Subjectivity". Infamous Desire: Male Homosexuality in Colonial Latin America, editado por Pete Sigal, University of Chicago Press, 2003, pp. 25-69.

Klor de Alva, J. Jorge. "Colonizing Souls: The Failure of the Indian Inquisition and the Rise of Penitential Discipline". Cultural Encounters: The Impact of the Inquisition in Spain and the New World, editado por Mary Elizabeth Perry y Anne J. Cruz, University of California Press, 1991, pp. 4-22.

Kramer, Heinrich y James Sprenger. The Malleus Maleficarum. 1848. Traducido por Montague Summers, Dover Publications, 1971.

Lancaster, Roger. Life Is Hard: Machismo, Danger, and the Intimacy of Power in Nicaragua. University of California Press, 1993.

Laqueur, Thomas. Making Sex: Body and Gender from the Greeks to Freud. Harvard University Press, 1990.

Las Casas, Bartolomé de. The Devastation of the Indies. 1552. Traducido por Herman Briffault, Johns Hopkins University Press, 1992.

Lavrín, Asunción. "Introduction: The Scenarios, the Actors, and the Issues". Sexuality and Marriage in Colonial Latin America, editado por Asunción Lavrín, University of Nebraska Press, 1989, pp. 1-35.

Lewis, Laura A. Hall of Mirrors: Power, Witchcraft and Caste in Colonial Mexico. Duke University Press, 2003.

---. "The 'Weakness' of Women and the Feminization of the Indian in Early Colonial Mexico". ColonialLatin American Review, vol. 5, n. ${ }^{\circ} 1,1996$, pp. 73-94.

Monter, William. Frontiers of Heresy: The Spanish Inquisition from the Basque Lands to Sicily. Cambridge University Press, 1990.

Montrose, Louis. “The Work of Gender in the Discourse of Discovery”. New World Encounters, editado por Steven Greenblatt, University of California Press, 1993, pp. 177-217.

Motolinía, Toribio. Historia de los indios de Nueva España. 1541. Herederos de Juan Gil, 1914.

Mott, Luiz. "Crypto-sodomites in Colonial Brazil". Infamous Desire: Male Homosexuality in Colonial Latin America, editado por Pete Sigal, University of Chicago Press, 2003, pp. 168-196.

Nanda, Serena. Gender Diversity: Crosscultural Variations. Waveland Press, 2000.

Nesvig, Martin. "The Complicated Terrain of Latin American Homosexuality". Hispanic American Historical Review, vol. 81, n. ${ }^{\text {s } 3-4, ~ 2001, ~ p p . ~ 689-730 . ~}$

Ortega, Sergio. “Teología novohispana sobre el matrimonio y comportamientos sexuales, 1519-1570”. De la santidad a la perversión, o de porqué no se cumplía la ley de Dios en la sociedad novohispana, editado por Sergio Ortega, Grijalbo, 1986, pp. 19-46.

Paz, Octavio. The Labyrinth of Solitude. Grove Press, 1961.

Perry, Mary Elizabeth. Gender and Disorder in Early Modern Seville. Princeton University Press, 1990. 
---. "Magdalens and Jezebels in Counter-Reformation Spain". Culture and Control in Counter-Reformation Spain, editado por Anne J. Cruz y Mary Elizabeth Perry, University of Minnesota Press, 1992, pp. 124-144.

Root, Deborah. "Speaking Christian: Orthodoxy and Difference in Sixteenth-Century Spain". Representations, n. ${ }^{\circ} 23$, verano de 1988, pp. 118-134.

Sánchez-Ortega, María Helena. "Women as a Source of 'Evil' in Counter-Reformation Spain". Culture and Control in Counter-Reformation Spain, editado por Anne J. Cruz y Mary Elizabeth Perry, University of Minnesota Press, 1992, pp. 196-215.

Sigal, Pete. "Gendered Power, the Hybrid Self, and Homosexual Desire in Late Colonial Yucatán". Infamous Desire: Male Homosexuality in Colonial Latin America, editado por Pete Sigal, University of Chicago Press, 2003, pp. 102-133.

---, editor. "(Homo)Sexual Desire and Masculine Power in Colonial Latin America: Notes toward an Integrated Analysis”. Infamous Desire: Male Homosexuality in Colonial Latin America. University of Chicago Press, 2003, pp. 1-24.

---, editor. Infamous Desire: Male Homosexuality in Colonial Latin America. University of Chicago Press, 2003.

Silverblatt, Irene. Moon, Sun, and Witches: Gender Ideologies and Class in Inca and Colonial Peru. Princeton University Press, 1987.

Stallybrass, Peter y Allon White. The Politics and Poetics of Transgression. Cornell University Press, 1986.

Stavig, Ward. "Political 'Abomination' and Private Reservation: The Nefarious Sin, Homosexuality, and Cultural Values in Colonial Peru”. Infamous Desire: Male Homosexuality in Colonial Latin America, editado por Pete Sigal, University of Chicago Press, 2003, pp. 134-151.

Taussig, Michael. Shamanism, Colonialism, and the Wild Man: A Study in Terror and Healing. University of Chicago Press, 1987.

Taylor, William B. Drinking, Homicide and Rebellion in Colonial Mexican Villages. Stanford University Press, 1979.

Trexler, Richard. Religion in Social Context in Europe and America: 1200-1700. University of Arizona Press, 2002.

---. Sex and Conquest: Gendered Violence, Political Order, and the European Conquest of the Americas. Cambridge University Press, 1995.

Van Young, Eric. "The New Cultural History Comes to Old Mexico". Hispanic American Historical Review, vol. 79, n. ${ }^{\circ}$ 2, 1999, pp. 211-247.

Weber, Alison. "Saint Teresa, Demonologist". Culture and Control in Counter-Reformation Spain, editado por Anne J. Cruz y Mary Elizabeth Perry, University of Minnesota Press, 1992, pp. 171-195.

Zamora, Margarita. Reading Columbus. University of California Press, 1993.

\section{Notas}

* Artículo de investigación. Esta investigación fue publicada por primera vez como "From Sodomy to Superstition: The Active Pathic and Bodily Transgressions in New Spain”. Ethnohistory, vol. 54, n. ${ }^{\circ}$ 1, invierno del 2007, pp. $129-157$.

1 Para no interrumpir la lectura, en las citas largas incluimos una traducción al español de la cita original en inglés. En este caso: "A primary eroticized constituent of its own fantasy life".

2 "Male homosexuality appeared so dangerous that men accused of homosexual behavior were isolated from others in the Royal Prison of Seville, their deviance regarded as a contagion that could easily infect others".

3 "Without moderation in goodness or vice".

4 "Unsavory reputation was not known".

5 "Ungroundedness of identities on which social structures and hierarchies developed".

6 "Laws against transvestism were often not taken seriously [...] [and] traditional Europeans in general were much readier to think of transvestism as a normal product of social interchange".

7 "Bodies concealed under robes are objects of suspicion".

8 "Interrogate[d] the rules of inclusion, exclusion and domination which structured the social ensemble".

9 "Sodomy was widely practiced".

10 "Father-monks and friars within a male ambiance, a subordination that often had a sexual component". 
11 "Shaped popular consciousness".

Licencia Creative Commons CC BY 4.0

Cómo citar este artículo: Lewis, Laura A. "De la sodomía a la superstición: el pasivo activo y transgresiones corporales en la Nueva España”. Cuadernos de Literatura, vol. 25, 2021.

https://doi.org/10.11144/Javerian a.cl25.sspa 